\title{
Artroplastia de suspensión-interposición de Zancolli modificada
}

\author{
H. Fahandezh-Saddi', A. Ríos², M. Villanueva ${ }^{3}$, D. Marín Guijarro ${ }^{4}$, \\ D. López ${ }^{4}$,G. Rodríguez Caravaca 5 ,M. del Cerro 6 \\ I Servicio de Cirugía Ortopédica y Traumatología. Hospital Universitario Fundación Alcorcón. Madrid. España. ${ }^{2}$ Servicio \\ de Cirugía Ortopédica y Traumatología. Centro Orthoindal, El Ejido. Almería. España. ${ }^{3}$ Servicio de Cirugía Ortopédica y \\ Traumatología. Hospital Universitario Gregorio Marañón. Madrid. España. ${ }^{4}$ Unidad de Cirugía de la mano y miembro \\ superior. Complejo Asistencial de Segovia. España. ${ }^{5}$ Servicio de Medicina Preventiva de Hospital Universitario Fundación \\ Alcorcón. Madrid. España. ${ }^{6}$ nnidad de Cirugía de la Mano. Hospital Beata María Ana. Madrid. España.
}

\begin{abstract}
Resumen: La artrosis de la base del pulgar es una de las patologías más frecuentes en la mano. Tras el tratamiento conservador, son muchos los tratamientos descritos para el tratamiento de la misma (artrodesis, artroplastia, artroplastia de interposición...). En el presente trabajo presentamos la técnica de Zancolli modificada para el tratamiento de la rizartrosis, Es una técnica quirúrgica fiable y reproducible para el tratamiento de la rizartrosis en estadio III-IV, con buenos resultados y bajo índice de complicaciones. Hemos desarrollado algún cambio técnico de la técnica original, que permite realizar la cirugía con una menor incisión y obtener tendones abductores accesorios de mayor longitud. Esto permite disminuir la morbilidad quirúrgica y en cierto modo disminuir las complicaciones, aumentando el volumen de suspensión-interposición. Una de las ventajas principales es el corto tiempo de inmovilización y los buenos porcentajes de pacientes libres de dolor (95\%) con una pinza estable y fuerte.
\end{abstract}

Palabras clave: Rizartrosis, artrosis trapeciometacarpiana, pulgar, trapeciectomía.

\begin{abstract}
Osteoarthritis of trapeziometacarpal joint is one of the most frequent patologies in hand surgery. After conservative treatment, there are several methods of treatment (arthrodesis, joint arthroplasty, trapeziectomy in isolation or in combination with tendon sling interposition or ligament reconstruction). In the current paper, we show the modified Zancolly arthroplasty for basal joint osteoarthritis. It is an easy and reproductible technique for the treatment of osteoarthritis of the thumb in Eaton stages III and IV, with good results and low grade of complications. We show several changes to the original technique, that allows us to make surgery with less surgical approach and to obtain abductor tendons of more length. This allows decreasing of surgical morbidity and decrease of complications, while we increase the volume of suspension and interposition tendons. The main advantage of this method is the short immobilization time and high percentage (95\%) of complete pain-free results and a stable and strong thumb in key pinches.
\end{abstract}

Key words: Rizoarthrosis, thumb osteoarthritis, thumb, trapeziectomy.

La artrosis de la articulación trapeziometacarpiana, es una patología frecuente en nuestro medio que origina dolor e incapacidad en la base del pulgar llegando a ser causa de pérdida severa de función. Afecta fundamentalmente a mujeres entre la $5^{\mathrm{a}}$ y $7^{\mathrm{a}}$ década de la vida siendo bilateral en el $30 \%$ de los casos y más frecuente en la mano dominante.

Se han propuesto numerosas hipótesis acerca de la etiología de la rizartrosis ${ }^{1-4}$ que incluyen la laxitud ligamentosa, la incongruencia articular, un posible efecto hormonal y la obesidad... Una de ellas es la teoría muscular, según la cual las inserciones del abductor accesorio incrementarían las fuerzas de compresión acelerando la degeneración articular tal y como ha descrito Zancolli-6.

Si bien existe un consenso general en cuanto al manejo inicial conservador de esta patología, el tratamiento quirúrgico ofrece buenos resultados en cuanto al alivio del dolor y mejoría de la fuerza y estabilidad. Existen numerosas técnicas quirúrgicas como son la trapezectomía simple ya propuesta por Gervis en 1949 - la trapezectomía asociada a la plastia de interposición-suspensión descrita inicialmente por Thompson, desarrollándose posteriormente numerosas variantes que se basan en el uso o no del flexor carpi radialis y en la reconstrucción o no del ligamento intermetacarpiano 5, 6, 10,11,12. Zancolli emplea el tendón abductor accesorio como tendón donante en la plastia de interposición tras trapezectomía para el tratamiento
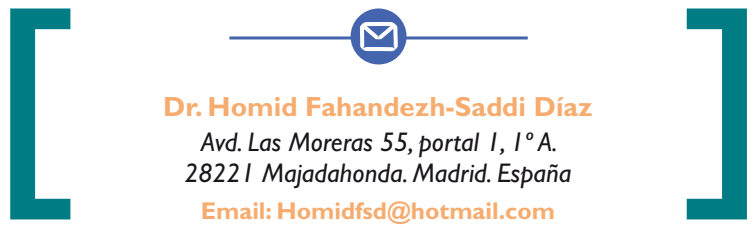

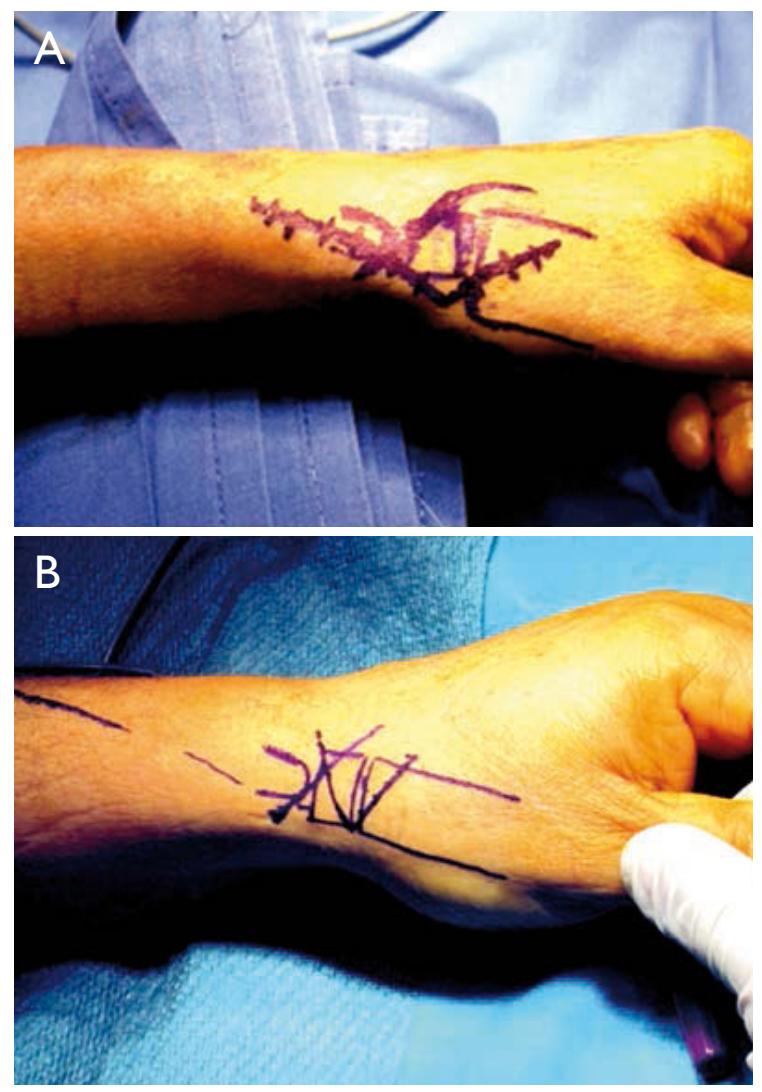

Figura || A y || B. Imágenes comparativas de incisión quirúrgica previa e incisión quirúrgica actual.

de la rizartrosis de acuerdo a su hipótesis, obteniendo buenos resultados. Las ventajas y complicaciones de todas estas técnicas se han mostrado en numerosas publicaciones. ${ }^{12,13,14,15 .}$

La resección del trapecio con interposición tendinosa ha sido el tratamiento más aceptado durante estos años, si bien en la actualidad existen estudios recientes que sugieren que la trapezectomía sola ofrece buenos resultados y que la interposición tendinosa no evita el acortamiento del primer radio a largo plazo ${ }^{12}$.

Presentamos la técnica de trapezectomía y la artroplastia de interposición-suspensión con el abductor accesorio según la técnica de Zancolli con dos modificaciones personales. La primera es la vía de abordaje, realizamos la técnica a través de dos incisiones, una en " $V$ " sobre el trapecio y otra transversa y proximal sobre el abductor del primer dedo (2) Figura I. La segunda es el cambio de la dirección del paso de la plastia en el túnel de la base del primer metacarpiano y el paso de la plastia alrededor del Flexor Carpi Radialis. (1) Figura 2.

\section{INDICACIONESY CONTRAINDICACIONES}

Esta técnica está indicada para el tratamiento de la artrosis de la articulación trapecio-metacarpiana en estadio II, III y IV de Eaton, siendo una técnica ideal para pacientes con baja demanda funcional y con una rizartrosis en estadio III y IV. Puede ser una buena técnica de salvamento ante el fracaso de otras técnicas quirúrgicas como la artroplastia total trapeciometacarpiana, la artrodesis u otro tipo de artroplastia de suspensión.

No está indicada en pacientes con alta demanda funcional y trabajo de fuerza. No puede realizarse en pacientes con cirugías previas y que presenten una rotura del flexor carpi radialis.

\section{ANATOMÍA QUIRÚRGICA}

Se centra la incisión cutánea sobre la articulación trapecio-metacarpiana. Tras incidir la piel, la primera estructura en riesgo es la rama sensitiva del nervio radial. Si realizamos una disección hacia cubital, nos encontramos el extensor largo del primer dedo, y si la hacemos hacia radial, vemos proximalmente a la base del primer metacarpiano los tendones del primer
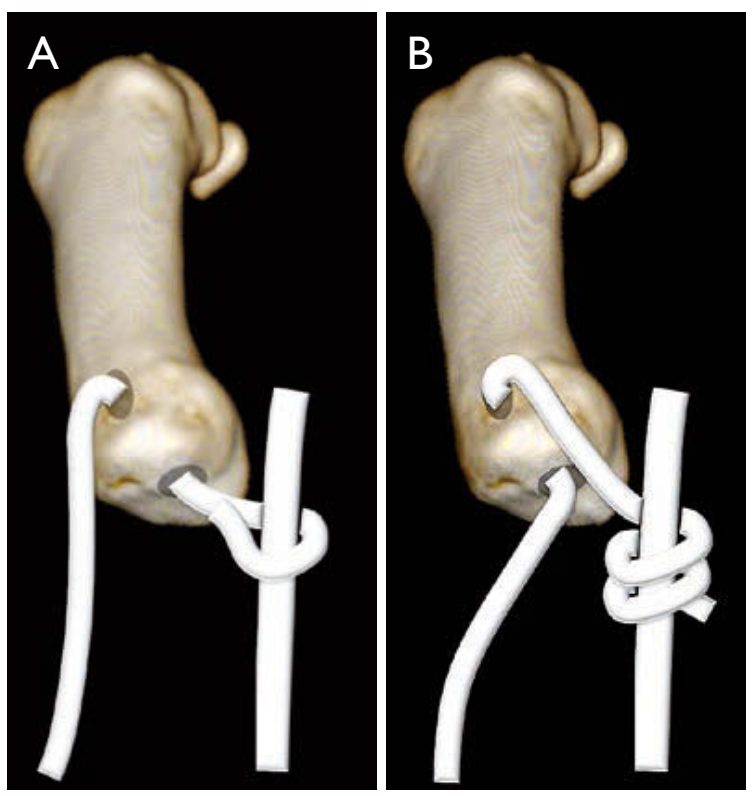

Figura 2. A. Técnica de Zancolli ER 6 . Paso de plastia desde el orificio dorsal en el trapecio hacia el orificio de la base y sutura de la plastia. B. Paso de la plastia desde el orificio en la base al orificio dorsal y sutura de la plastia alrededor del FCR, tras varios bucles. 


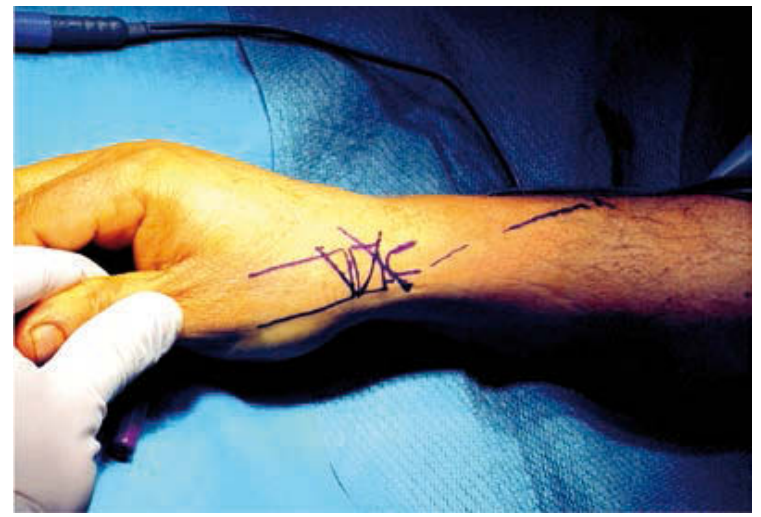

Figura 3. Incisión de vértice volar centrada sobre la articulación trapecio-metacarpiana.

compartimento extensor. El acceso a la articulación se encuentra entre los dos grupos tendinosos. Abrimos la fascia que se encuentra sobre la cápsula articular y, proximalmente a la articulación trapecio-metacarpiana, se encuentra la rama dorsal de la arteria radial que cruza el campo quirúrgico. Esta es la referencia para identificar la articulación entre trapecio y escafoides. Proximalmente y en el borde lateral del radio, tenemos el primer compartimento extensor. Hay que tener precaución porque justo en su superficie se encuentra el nervio radial superficial. En el interior de este compartimento que tiene aproximadamente I cm de longitud, tenemos los siguientes tendones:

- Tendón del extensor corto, ausente en un 5\% de los pacientes.

- El tendón del abductor largo del pulgar, es un tendón que se encuentra volar al anterior, y realiza la abducción del primer metacarpiano.

- Tendones abductores accesorios, son tendones que se encuentran en un número variable en el interior de este compartimento, volares al abductor largo del primer dedo, con longitud y grosor variable.

\section{TÉCNICA QUIRÚRGICA}

- Se inicia el procedimiento con una incisión en "V" de vértice palmar, centrada en la articulación trapeciometacarpiana. (2) Figura 3.

- Es muy importante identificar y proteger las ramas sensitivas del nervio radial. No disecamos de rutina toda la longitd del nervio, sino que lo dejamos protegido en su grasa y accedemos tras localizarlo al plano más profundo. Figura 4A y B.
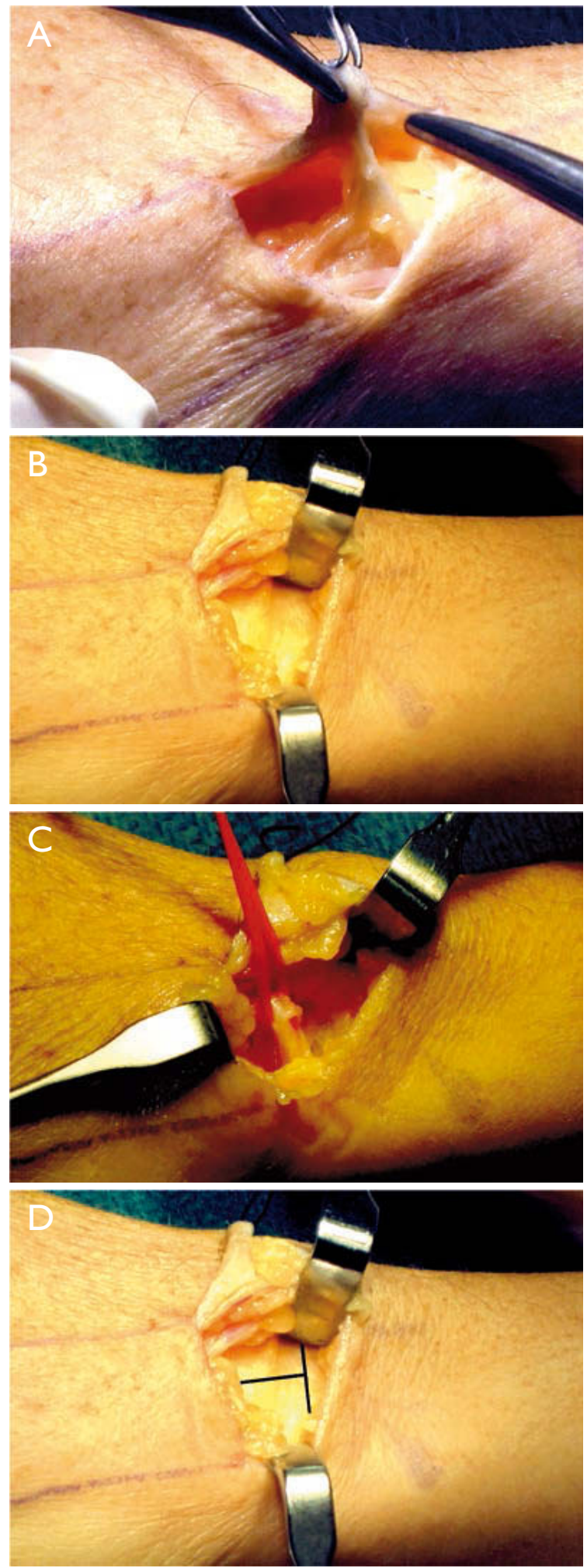

Figura 4. A. Identificación de nervio radial. B. Protección de nervio radial, que dejamos englobado en su grasa y acceso a plano profundo. C. Identificación de arteria radial y coagulación con bipolar de vasos que penetran la capsula articular. D. Capsulotomía en T. 


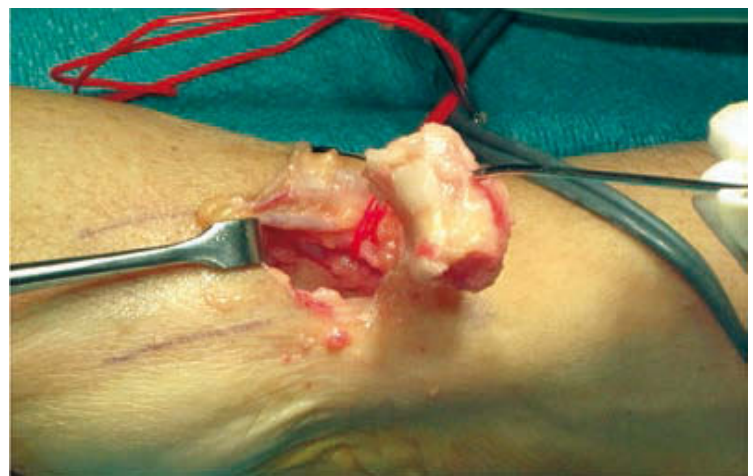

Figura 5. Trapecectomía completa utilizando una aguja de Kirschner para facilitar su extracción tras la liberación del mismo sin lesionar el flexor carpi radialis.

- Identificamos la rama dorsal de la arteria radial, que cruza sobre la cápsula de la articulación trapecioescafoidea. Se coagulan todos los pequeños vasos que, desde la arteria radial, entran a la cápsula. La localización de la arteria radial es la referencia para identificar la articulación trapecio-escafoidea. (1) Figura 4C.

- A continuación se procede a la capsulotomía en "T". Este es un punto importante de la técnica, ya que la rama horizontal de la "T" debe localizarse sobre la articulación trapecio-escafoidea y la vertical sobre el trapecio y la base del metacarpiano. (2) Figura 4D.

- Una vez seccionada la cápsula, se despega del trapecio y se expone éste completamente. Es importante, especialmente en la zona más proximal y radial, el despegar con periostotomo el trapecio, controlando siempre la punta del bisturí ya que el tendón del flexor carpi radialis (FCR) está muy próximo al trapecio y polo distal del escafoides en esa localización.

- Hacemos una osteotomía del trapecio, y lo extraemos completamente usando una pequeña gubia. Hay que hacer hincapié en la identificación del osteofito cubital del trapecio, para extirparlo. Un detalle técnico que lo puede facilitar consiste en colocar una aguja de Kirschner de 1,6 mm centrada en el trapecio para poder manipularlo. Una vez que soltamos la articulación entre trapecio y trapezoide, se introduce un periostotomo a través de esa articulación, siempre muy pegado al trapecio y vamos despegando el trapecio en una dirección que va de cubital a radial. De esa forma, especialmente en mujeres, conseguimos de una forma más sencilla extraer completamente el trapecio. Si la extracción

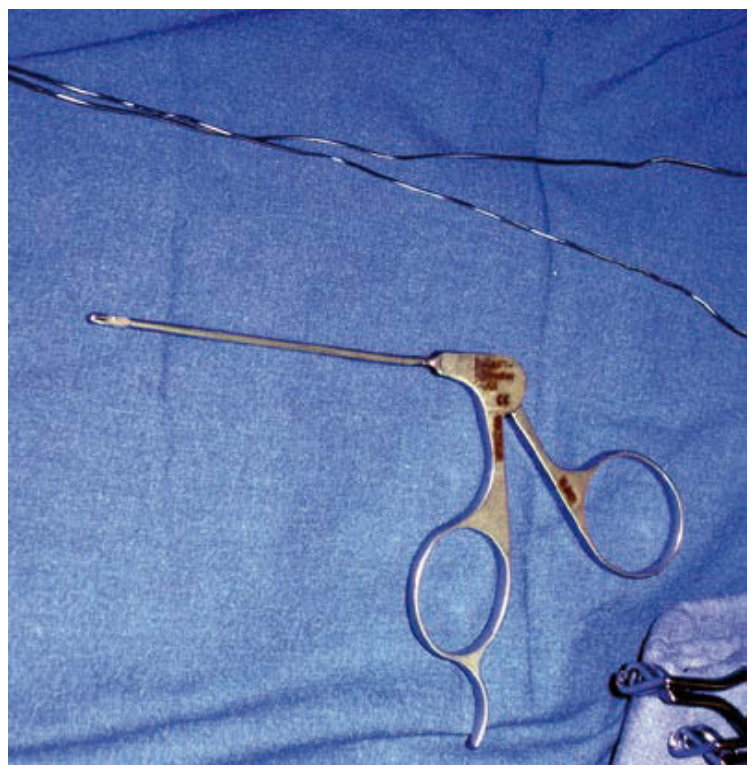

Figura 6. Instrumentos para obtener injerto tendinoso para plastia: pinza de basket de artroscopia de muñeca y alambre del 0'8.

es muy dificultosa, extraemos el mismo fragmentándolo con una gubia @ Figura 5.

- En la técnica que antes realizábamos, se exponía el primer compartimento extensor y se abría éste en su zona dorsal. Posteriormente se identificaban secuencialmente los tendones del extensor corto del pulgar, abductor largo del pulgar y el abductor accesorio, obteniendo este último tras su tenotomía proximal para utilizarlo como plastia de interposición.

Actualmente estamos realizando este procedimiento de una forma menos agresiva e invasiva con un alambre y un basket @ Figura 6. Tras identificar distalmente al primer compartimento extensor los tendones que lo constituyen, buscamos el tendón más volar que es el abductor accesorio. Podemos encontrarnos un número variable de tendones abductores accesorios y con distintos calibres. $\mathrm{Si}$ es muy fino, podemos usar dos o tres de estos tendones para la plastia u obtener también la mitad volar del abductor largo del pulgar.

- Identificamos el abductor accesorio y pasamos alrededor de él un hilo de Nylon Monofilamento del 0 , y lo anudamos a modo de bucle. (2) Figura 7A. Tras la separación de los tendones, introducimos por el interior del primer compartimento extensor una pinza de basket de artroscopia de muñeca o un 

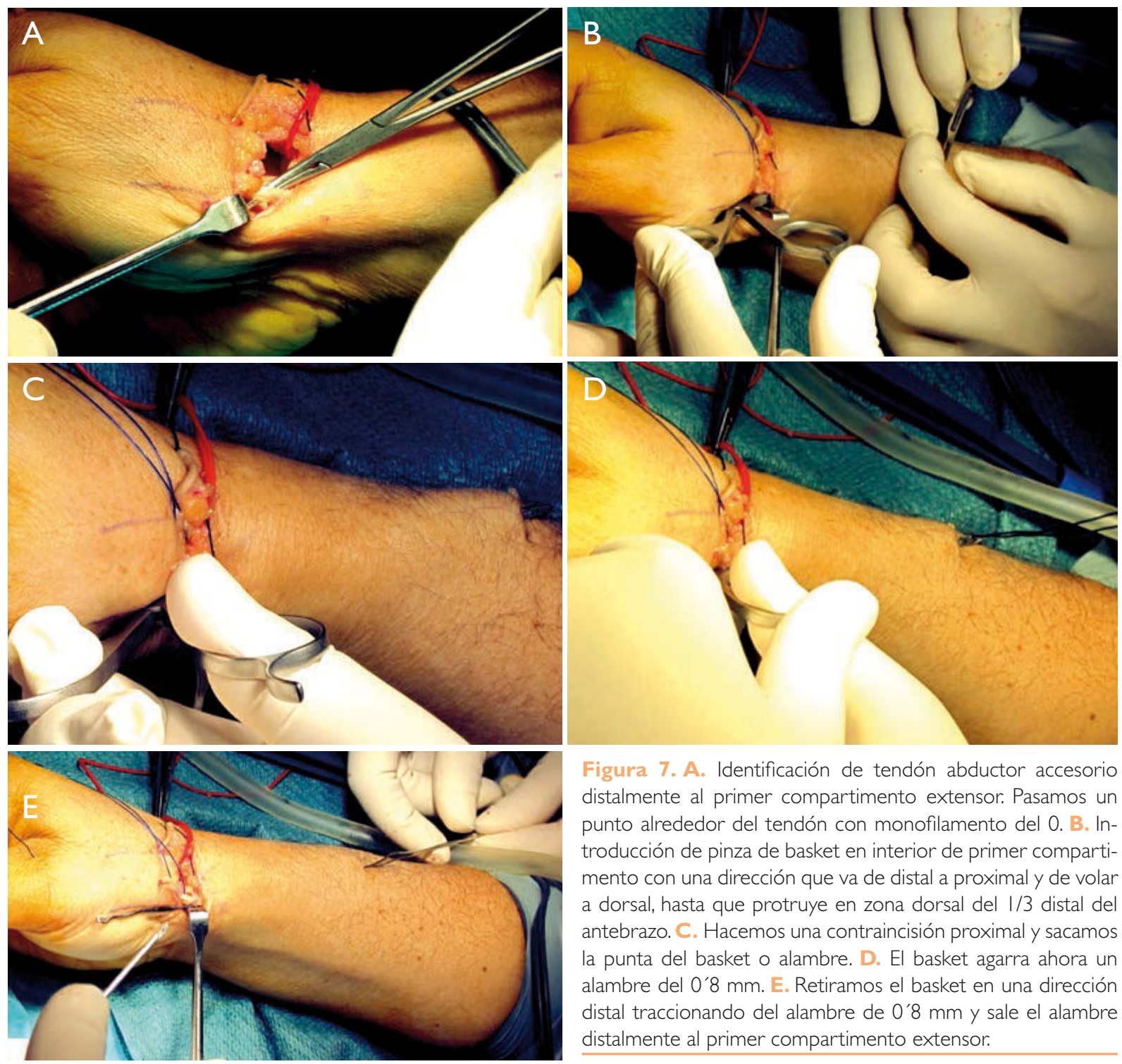

Figura 7. A. Identificación de tendón abductor accesorio distalmente al primer compartimento extensor. Pasamos un punto alrededor del tendón con monofilamento del 0. B. Introducción de pinza de basket en interior de primer compartimento con una dirección que va de distal a proximal y de volar a dorsal, hasta que protruye en zona dorsal del I/3 distal del antebrazo. C. Hacemos una contraincisión proximal y sacamos la punta del basket o alambre. D. El basket agarra ahora un alambre del 0’8 mm. E. Retiramos el basket en una dirección distal traccionando del alambre de 0’8 mm y sale el alambre distalmente al primer compartimento extensor.

alambre trenzado del número I, en una dirección que va de distal a proximal y de volar a dorsal. Es importante no notar resistencia, y que el alambre o basket discurra fácilmente. (1) Figura 7B.

Al empujar el alambre o el basket, vemos cómo protruye en la zona dorsal y distal del antebrazo. (4) Figura 7C, Hacemos una incisión mínima de unos $2 \mathrm{~mm}$ en esa localización y extraemos la punta del alambre. Pasamos ahora en sentido contrario otro alambre de 0'8 mm que cogemos con el basket o introducimos en el ojal distal del alambre. (9) Figura 7D y E.Tiramos del alambre del "I" en dirección distal, de tal forma que el alambre de 0’8 aparezca justo distal al primer compartimento

extensor. Ahora se anuda el punto que habíamos pasado alrededor del tendón abductor accesorio al alambre de 0’8, y se tira de ese alambre hacia proximal. (1) Figura 8A y 8B, Con este gesto lo que conseguimos es realizar una disección del tendón incluso por encima de la zona de músculo proximal y obtener una disección tendinosa de aproximadamente $12 \mathrm{~cm}$ de longitud. Al tirar del alambre hacia proximal, vemos cómo, por el ojal cutáneo creado proximalmente, aparece el punto de Nylon monofilamento del " 0 ". En ese momento identificamos el tendón disecado y hacemos la tenotomía lo más proximal posible. (a) Figura 8C. En situaciones en las que el tendón tiene buen calibre a ese nivel, podemos realizar de nuevo la misma operación y 

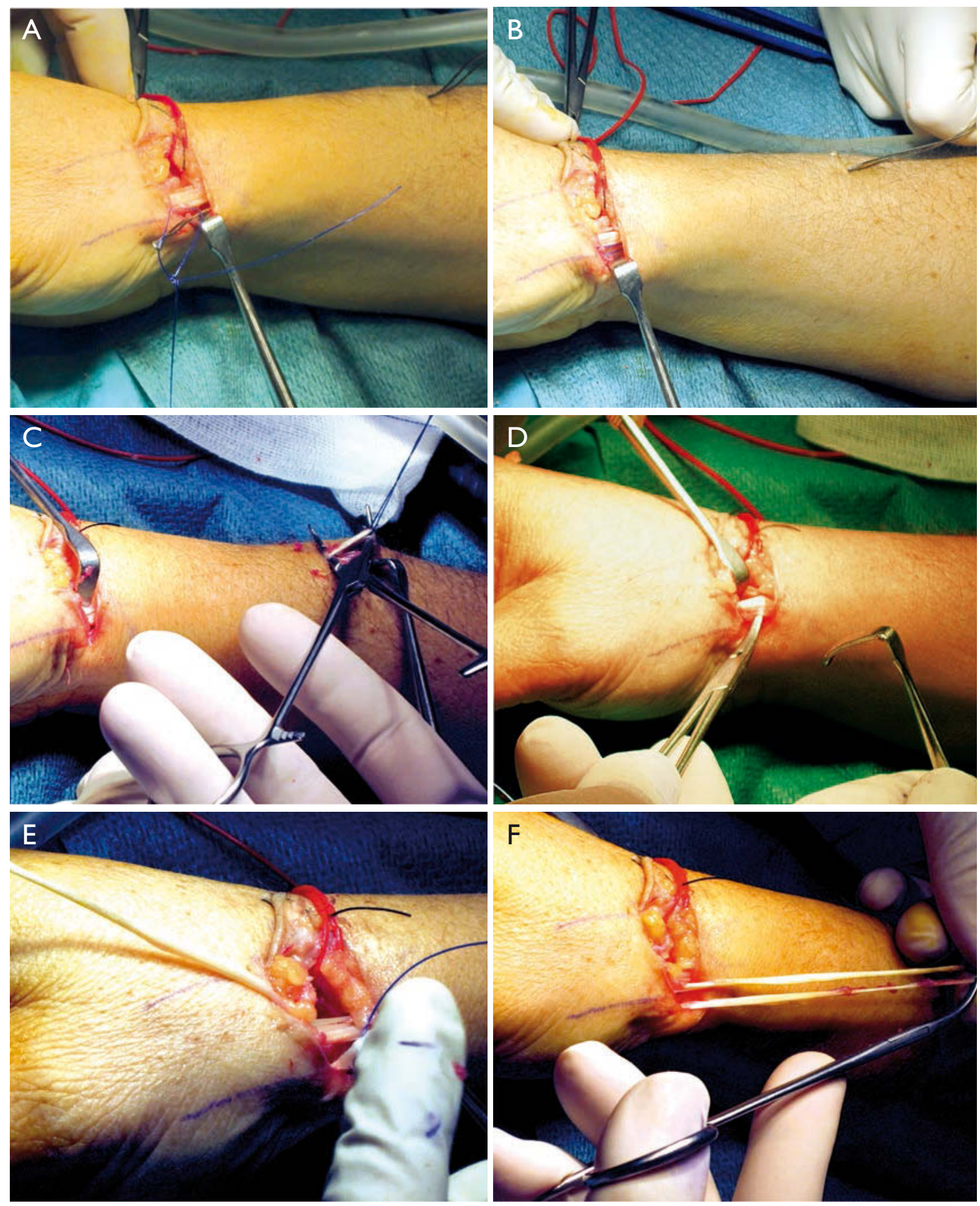

Figura 8. A. Anudamos el hilo de monofilamento del 0 que habíamos pasado previamente alrededor del abductor accesorio al alambre que hemos pasado. B. Tracción proximal del alambre, y el hilo diseca de distal a proximal el abductor accesorio hasta exponerlo proximalmente en la incisión dorsal. C. Identificación del tendón lo más proximal posible y tenotomía con un bisturí. D. Recuperación del tendón abductor accesorio distalmente. E. Recuperación del tendón abductor accesorio distalmente, dejándolo insertado distalmente. F. Si fuera preciso podemos repetir este gesto y obtener varios tendones para la plastia. 

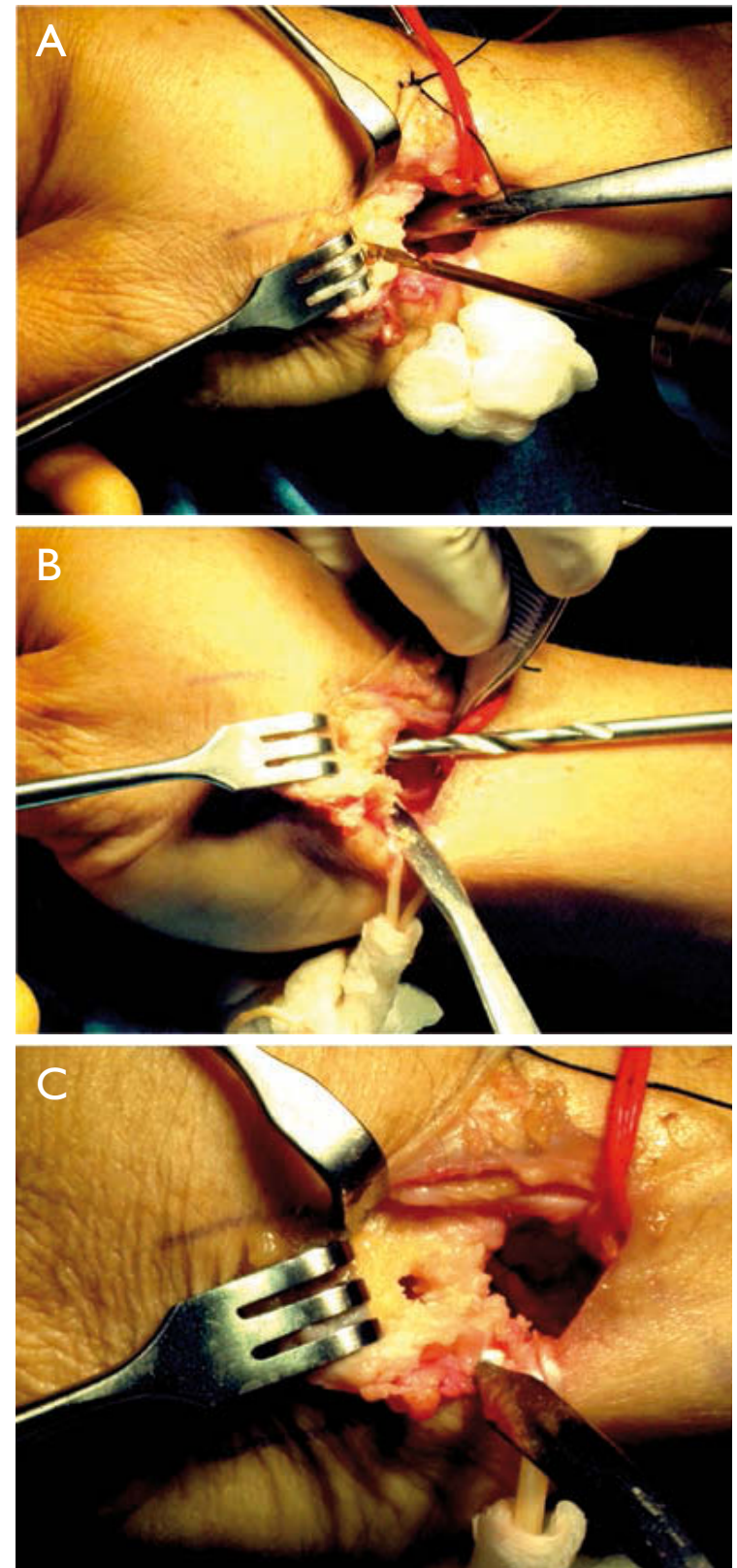

Figura 9. A. Perforamos la cortical dorsal del primer metacarpiano con una broca de 2'5 mm primero y 3'5 después. Es un túnel monocortical. B. Perforamos el centro de la base del primer metacarpiano con broca de 2'5 mm primero y 3'5 mm después. C. Hemos creado un túnel en "L" que limpiamos con una cucharilla.

extraer un tendón de más longitud. Una vez seccionado el tendón debemos recuperarlo distalmente. (1) Figura 8D.

- En la zona distal al primer compartimento extensor, identificamos los tendones que hemos disecado, y al tirar de ellos con un mosquito o una
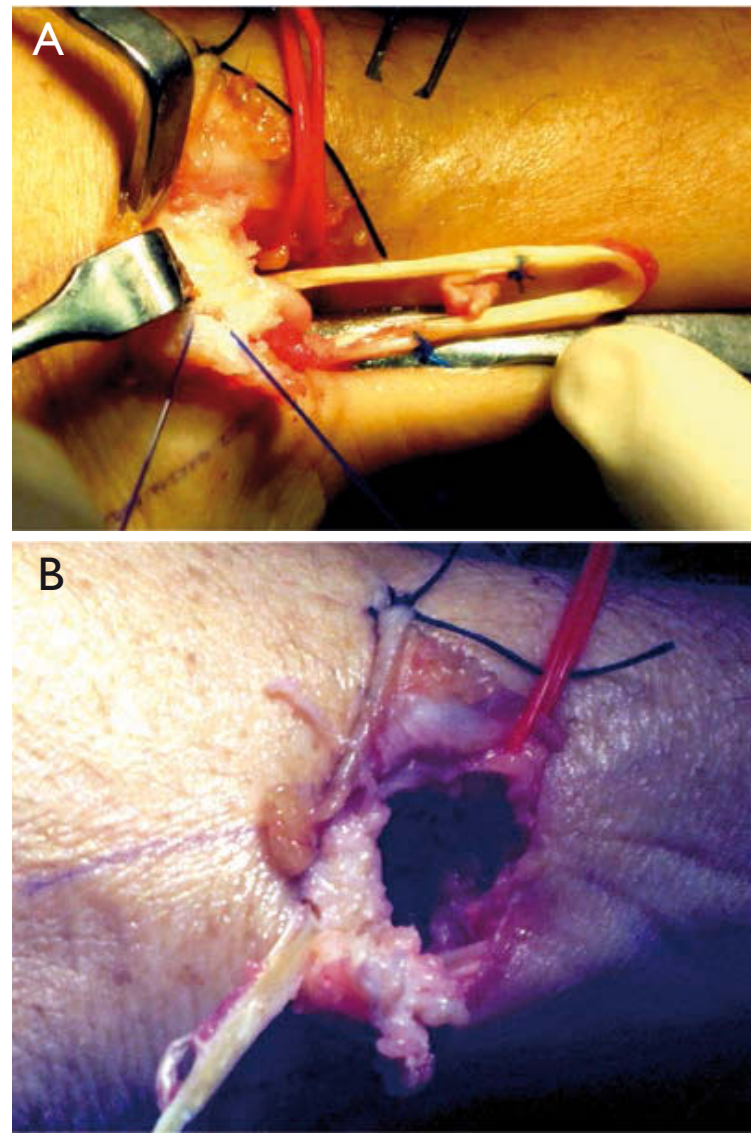

Figura | 0. A. Tras pasar el tendón donante por debajo de los tendones del extensor corto y abductor largo, tunelizamos los tendones desde la base del primer metacarpiano al dorso. B. Extraemos el tendón por la zona dorsal del metacarpiano.

pinza, recuperamos el tendón que hemos seccionado proximalmente y que usaremos para la plastia. En este momento disecamos el tendón hasta llegar a su inserción distal, habitualmente en la musculatura tenar, pero sin debilitarla. (c) Figura 8E y 8F.

- Tunelizamos el tendón a través de la cápsula por debajo de los tendones abductor largo y extensor corto y lo llevamos a la zona donde hemos realizado la trapezectomía. Este punto es importante para no atrapar durante la plastia esos tendones y tener una limitación posterior de la movilidad y dolor por roce.

- Se realiza un túnel óseo con una broca de 2,5mm en la zona dorso-radial del primer metacarpiano en dirección al centro de la base del primer metacarpiano, ampliándose posteriormente con una broca de 3,5 mm. Hacemos un segundo orificio en 

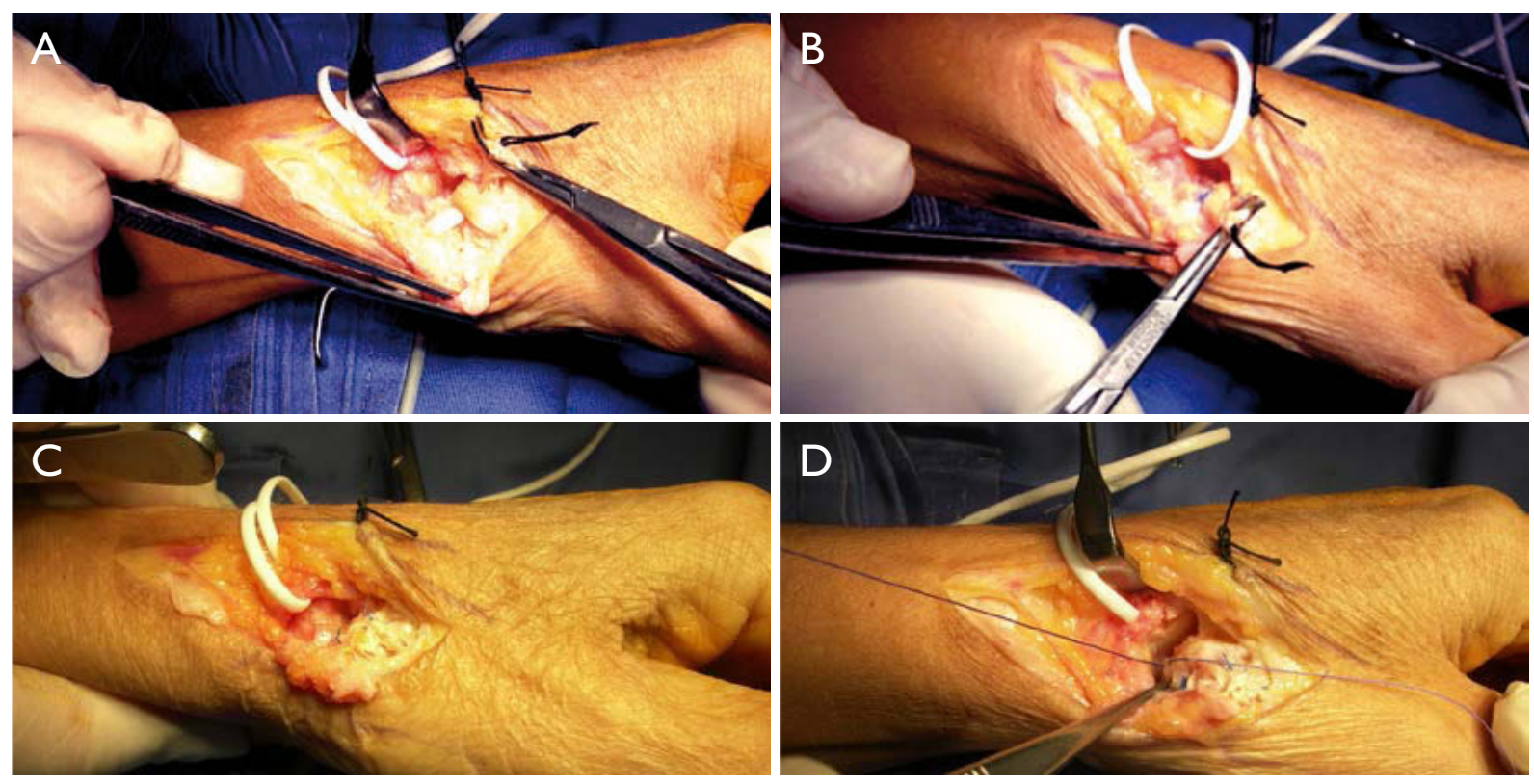

Figura II.A. Tracción longitudinal del primer dedo, y pasada del tendón abductor accesorio alrededor del FCR. B. Realizamos sutura con monofilamento no reabsorbible de 3/0 tras pasar el tendón abductor accesorio alrededor del FCR. Repetimos este gesto tantas veces como sea posible suturando con varios puntos la plastia. Importante no soltar tracción del primer dedo. C. Imagen de la plastia finalizada rellenando el hueco de la trapecectomía y suspendiendo el primer metacarpiano. D. Protección de la reparación con los restos capsulares.

el centro de la base del primer metacarpiano con las brocas anteriormente mencionadas y limpiamos con una cucharilla para comunicar ambos túneles (d) Figura 9A-C.

- A diferencia de la técnica original descrita por Zancolli según la cual tuneliza el tendón desde dorsal hacia la base, nosotros lo tunelizamos en sentido inverso, es decir, desde la base hacia el dorso, manteniendo la tracción en todo momento. Zancolli no le da importancia a la suspensión, nosotros sí y por eso realizamos una tracción del dedo manteniéndola hasta acabar la plastia (2) Figuras I0A y B.

- A continuación pasamos el tendón alrededor del flexor carpi radialis realizando tantas lazadas como sea posible utilizando una sutura no reabsorbible de 3/0. Normalmente pasamos 5 pasadas alrededor del FCR, dando puntos de seguridad para mantener esa lazada (8) Figuras IIA-C.

- Finalmente realizamos el reanclaje de la cápsula articular con sutura reabsorbible de 3/0 proporcionando mayor protección a la plastia y a la base del primer metacarpiano (a) Figura IID.

- Soltamos la isquemia y hacemos hemostasia cuidadosa.
- Suturamos la piel con Nylon monofilamento no reabsorbible de $4 / 0$.

\section{MANEJO POSTOPERATORIO}

Al finalizar la intervención quirúrgica, se coloca una férula de yeso larga incluyendo el primero dedo y una pequeña férula más fina que la anterior que, a modo de corbata, mantiene la primera comisura abierta.

A los 5-7 días, se sustituye la anterior férula de yeso por una férula de inclusión de primer dedo corta termoplástica.

El paciente permanece inmovilizado hasta la tercera semana, momento en que se remite a rehabilitación. Se comienza entonces la movilización pasiva, en nuestra experiencia, la mayor parte de los pacientes realizan ya una movilización activa a partir de $4^{\mathrm{a}}$ semana.

\section{COMPLICACIONES}

- La neuropatía transitoria de la rama sensitiva del nervio radial, es una de las complicaciones más frecuentes. Habitualmente se trata de una neuroapraxia que se resuelve al cabo de 4-6 semanas. 

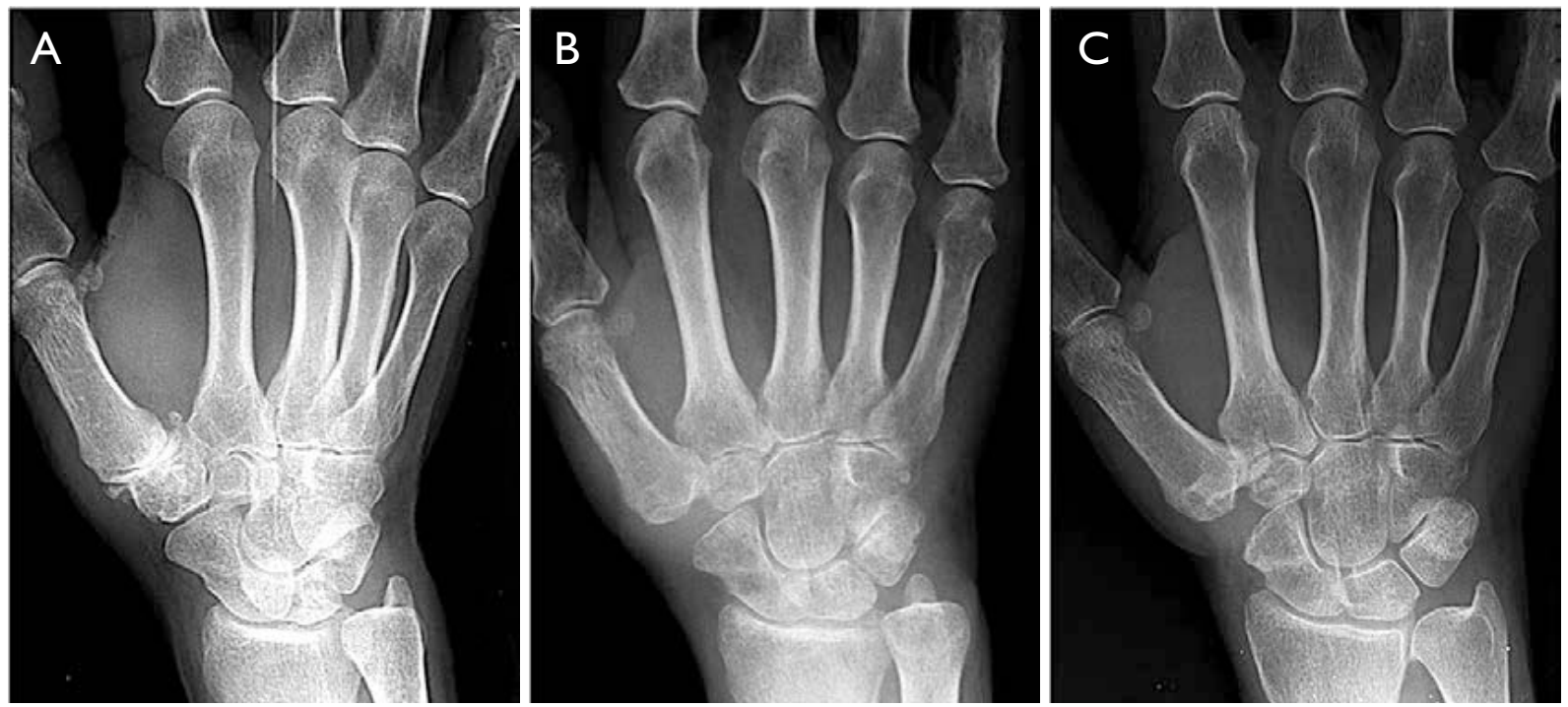

Figura II A. Radriografía AP preparatoria. B. Radiografía AP a los seis meses. C. Radiografía AP a los dieciocho meses.

- La lesión de la arteria radial o el sangrado postquirúrgico de algunas de sus ramas perforantes. Es importante soltar isquemia y hacer hemostasia cuidadosa para evitar esta complicación.

- Extracción de un tendón donante corto. Esto ocurre cuando el vientre muscular es muy distal y el tendón fino. Podemos solventar este problema extrayendo la mitad volar del abductor largo del pulgar.

- Colapso del primer metacarpiano. Al igual que otras artroplastias de suspensión-interposición, es posible si el ligamento intermetacarpiano está roto, que se colapse la base del primer metacarpiano. La velocidad de colapso es muy variable, habiendo pacientes en los que pasa mucho tiempo hasta que esto aparece. La plastia cápsular ayuda a que si existe un colapso no haya roce entre la base del primer metacarpiano y el escafoides.
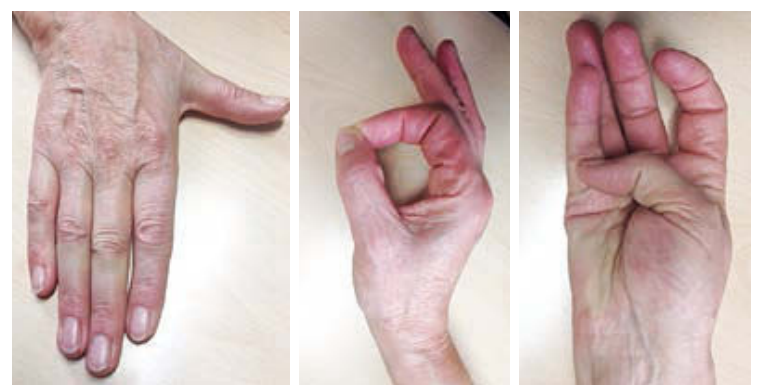

Figura I13. Movilidad a los dieciocho meses de la intervención quirúrgica.
- Dolor residual y rigidez. Esto puede ocurrir si la inmovilización es prolongada. El dolor residual puede ser secundario a un pequeño neuroma, a una artrosis entre escafoides y trapezoide o por inestabilidad proximal de la base del primer metacarpiano.

- Algodistrofia.

\section{CASO CLÍNICO}

Se trata de una paciente de 68 años de edad, diestra, presenta dolor en primer dedo de la mano, con impotencia funcional para abrir botes de un año de evolución. Refiere que se le caen objetos de la mano. Y no presenta parestesias ni otra sintomatología neurológica.

A la exploración presenta dolor a nivel de la base de primer metacarpiano, presenta dolor a la retroposición del pulgar, con maniobras de Grind test y Crank test positivas. Se evidencia disminución de fuerza de puño y de pinza en relación con lado contralateral.

El estudio radiológico evidencia artrosis trapeciometacarpiana en estadio Eaton III (4) Figura I2A.

Se remite a la paciente a terapia ocupacional y se coloca ortesis inmovilizadora para intento de control del dolor. La paciente no evoluciona de forma satisfactoria, presentando dolor incapacitante. Se realiza 
infiltración con mepivacaína y metil prednisolona, sin obtener tampoco mejoría clínica.

Dado el fracaso de tratamientos previos, se decide realizar una intervención quirúrgica mediante técnica de artroplastia de suspensión-interposición de Zancolli modificada. La cirugía se desarrolla sin complicaciones. Tras la intervención quirúrgica, la paciente se inmovilizó durante tres semanas, iniciando en ese momento el tratamiento rehabilitador.

A las 6 semanas se evidencia muy buena movilidad del pulgar y de la mano, se retira la ortesis de forma definitiva. La paciente desde ese momento y de forma progresiva, realiza las actividades de su vida cotidiana.

A los 6 meses la paciente presenta una buena evolución clínica y radiológica, sin complicaciones evidentes. No se evidencia colapso de la base del primer metacarpiano (a) Figura I2B. La evolución clínica y radiológica se mantiene estable a los 18 meses de la intervención quirúrgica (4) Figura I2C y Figura I 3.

\section{CONFLICTOS DE INTERESES}

Los autores declaran no tener conflictos de intereses.

\section{BIBLIOGRAFÍA}

I. Adams JE, Merten SM, Steinmann SP. Arthroscopic interposition arthroplasty of the first carpometacarpal joint. J Hand Surg. 2007;32(3):268-7.

2. Anwar R, Cohen A, Nicholl JE. The gap after trapeziectomy: a prospective study. J Hand Surg. 2006;31:5: 566-8

3. Atroshi I, Axelsson G, Hasslehom OT. Extensor carpi radialis longus tendon arthroplasty in the treatment of primary trapeziometacarpal arthrosis. J Hand Surg. 1997; 22A:419-27.

4. Zancolli E, Aponte F, Zancolli E. Artrosis trapeciometacarpiana Capsuloplastia con estabilización metacarpiana activa. Rev Soc Arg Cirug Mano. | $981 ; 1:$ |3-21.
5. Zancolli EA,Zancolli ER, Cagnone JC. Rizartrosis del pulgar. Tratamiento quirúrgico en estados iniciales y tardíos. Rev Iberamer Cir Mano. 2000(57)8- I8.

6. Zancolli ER, Andrés BG. The modified Zancolli arthroplasty for basal thumb arthritis. Tech Hand Up Extrem Surg. 2010 Dec; |4(4):248-51.

7. Belcher HJCR, Nicholl JE. A comparison of trapeziectomy with and without ligament reconstruction and tendon interposition. J Hand Surg. 2000;25B: 4: 350-6.

8. Brunelli G, Monini L, Brunelli F. Stabilisation of the trapeziometacarpal joint. J Hand Surg. 1989; | 4B:209- 12.

9. Burton RI, Pellegrini VD Jr. Surgical management of basal joint arthritis of the thumb. Part II. Ligament reconstruction with tendon interposition arthroplasty. J Hand Surg. 1986; I I A:324-32.

10. Cooney WP, Leddy TP, Larson DR. Revision of thumb trapeziometacarpal arthroplasty. J Hand Surg. 2006;31A:219.el-219.el0.

I I. Damen A, Groningen B.van der Lei, Leeuwarden P.H.Robinson et al. Carpometacarpal arthritis of the thumb. J Hand Surg. 1996;2 I A:807-12.

12. Davis TRC, Brady O, Barton NJ et al.Trapeziectomy alone, with tendon interposition or with ligament reconstruction ?. J Hand Surg. 1997;22B:6:689-94.

13. Davis TRC, Brady O, Dias JJ. Excision of the trapezium for osteoarthritis of the trapeziometacarpal joint: A study of the benefit of ligament reconstruction or tendon interposition. J Hand Surg. 2004;29A: I069-77.

14. Field J, Buchanan D. To suspend or not to suspend: A randomised single blind trial of simple trapeziectomy versus trapeziectomy and flexor carpi radialis suspension. J Hand Surg. 2007;32(4):462-6.

15. Lamas C, Morro M, Llusa M, Mustafa A, Proubasta I. Relación de la inestabilidad, la laxitud ligamentosa y la traslación del metacarpiano sobre el trapecio en la aparición de la artrosis trapecio metacarpiana: Estudio anatómico. Rev Iberoamer Cir Mano 2013:4I (I):40-5. 